\title{
Anti-neutrophil cytoplasmic antibody- associated pauci-immune glomerulonephritis in a patient with chronic lymphocytic leukaemia
}

\author{
CS Yeung ${ }^{1}$, MB, BS, MRCP, CY Cheung ${ }^{1}$ *, PhD, FHKAM (Medicine), PT Chan², MB, BS, FHKAM (Pathology), \\ John W Li', MB, BS, MRCP, WL Chak', FRCP, FHKAM (Medicine), KF Chau', FRCP, FHKAM (Medicine)
}

Departments of ${ }^{1}$ Medicine and ${ }^{2}$ Pathology, Queen Elizabeth Hospital, Jordan, Hong Kong

*Corresponding author: simoncycheung@gmail.com

Hong Kong Med J 2016;22:178-80

DOI: 10.12809/hkmj144421

\section{Case report}

A 71-year-old woman presented to us in August 2012 with a rash over both lower limbs. Blood tests revealed leukocytosis with white cell count of $22 \times 10^{9} / \mathrm{L}$ (neutrophil $1.6 \times 10^{9} / \mathrm{L}$, lymphocytes $20 \times 10^{9} / \mathrm{L}$ ). Serum creatinine level was $53 \mu \mathrm{mol} / \mathrm{L}$ and serum albumin $42 \mathrm{~g} / \mathrm{L}$. Urinalysis showed no albuminuria or microscopic haematuria. Bone marrow biopsy confirmed the diagnosis of chronic lymphocytic leukaemia (CLL). Fluorescence in-situ hybridisation showed deletion of chromosome 11q22 23. Computed tomography revealed multiple enlarged lymph nodes in different regions such as submental, bilateral jugular, left supraclavicular fossa, mediastinal, hila, axillary, porta hepatis, para-aortic and bilateral common iliac regions. Chlorambucil $2 \mathrm{mg}$ twice weekly was prescribed and the patient was followed up regularly in our clinic. During this period she had two episodes of sepsis that were treated successfully with antibiotics.

In October 2013, she was noted to have progressive bilateral lower limb swelling and facial puffiness. She also reported frothy urine but no gross haematuria. She denied taking any herbs or over-the-counter medication. Physical examination was unremarkable except for pitting oedema over both lower limbs. Urinalysis revealed the presence of 10-50 red blood cells $/ \mathrm{cm}^{2}$. The spot urine protein-to-creatinine ratio was $13.1 \mathrm{~g} / \mathrm{g}$. Her serum creatinine concentration was $364 \mu \mathrm{mol} / \mathrm{L}$ (reference range [RR], $65-100 \mu \mathrm{mol} / \mathrm{L}$ ), albumin was $32 \mathrm{~g} / \mathrm{L}$ (RR, 35-52 g/L), globulin was $40 \mathrm{~g} / \mathrm{L}$ (RR, 22-36 g/L), haemogloblin was $87 \mathrm{~g} / \mathrm{L}(\mathrm{RR}, 134-171 \mathrm{~g} / \mathrm{L})$, and white blood cell count was $26.4 \times 10^{9} / \mathrm{L}$ (RR, 3.7-9.2 x $10^{9} / \mathrm{L}$ ) [neutrophil $3.9 \times 10^{9} / \mathrm{L}$, lymphocytes $22.1 \times$ $\left.10^{9} / \mathrm{L}\right]$. The liver function was normal. Anti-nuclear antibody was positive (titre 1:80, homogeneous pattern) but anti-DNA was negative. Her antineutrophil cytoplasmic antibodies (ANCA) were positive with perinuclear staining pattern (pANCA) and the anti-myeloperoxidase (anti-MPO) antibody titre was $>100 \mathrm{U} / \mathrm{mL}$ (reference level, $<5 \mathrm{U} / \mathrm{mL}$ ). The complement level was normal and hepatitis serology was negative. Urine culture showed no bacterial growth. Ultrasound-guided renal biopsy was performed. Light microscopic examination showed 21 glomeruli, three of which showed global glomerulosclerosis (Fig 1). Twelve glomeruli featured crescent formation ( 3 had cellular crescent, 6 had fibrocellular crescent, and 3 had fibrous crescent). Fibrinoid necrosis was also identified. Nonetheless, immunohistochemical staining showed several atypical lymphoid cell aggregates composed of small- to medium-sized lymphoid cells expressing B-cell markers CD20, CD5, CD23 and LEF-1 (Fig 2). They were negative for T-cell marker CD3, follicular centre marker CD10 and cyclin D1. The overall features supported the diagnosis of

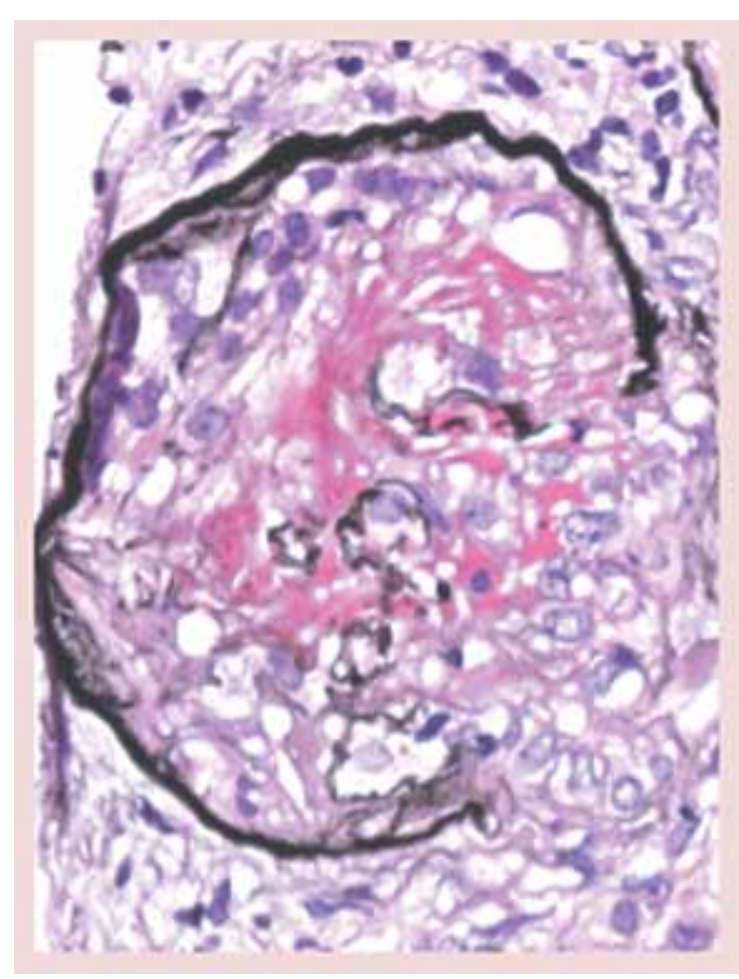

FIG I. One of the glomeruli shows rupture of glomerular basement membrane with fibrinoid necrosis under light microscopy (PASM stain; original magnification, $x$ 400) 


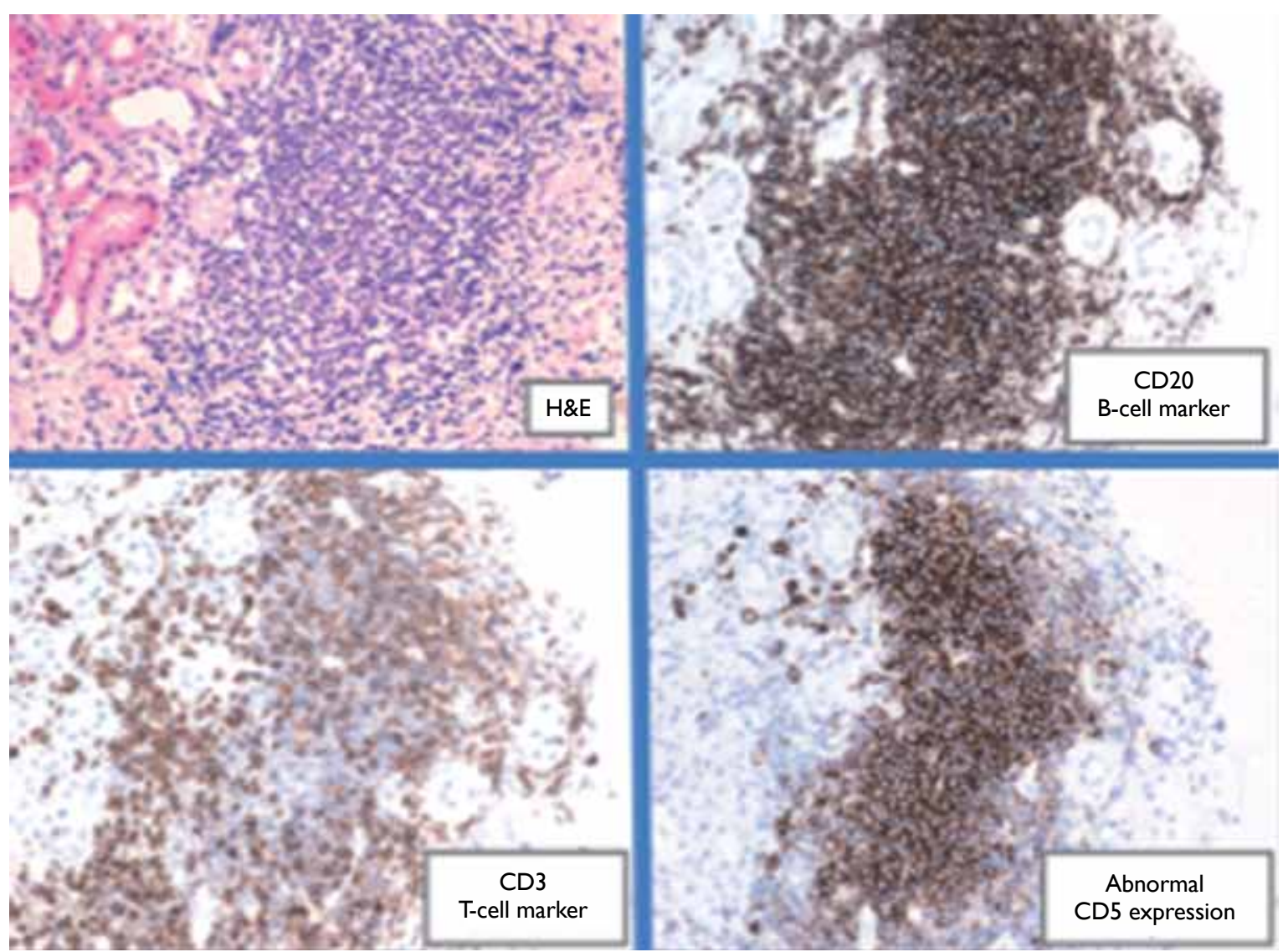

FIG 2. Immunohistochemical study shows presence of several atypical lymphoid cell aggregates composed of small- to mediumsized lymphoid cells expressing B-cell marker CD20 and CD5 with negative CD3 (immunostain with polymer/multimer DAB detection system on paraffin embedded sections; original magnification, $x$ 100)

ANCA-associated crescentic glomerulonephritis and renal involvement of CLL. She was given 3 days of intravenous pulse methylprednisolone 500 $\mathrm{mg}$, followed by daily oral prednisolone $30 \mathrm{mg}$ and cyclophosphamide $50 \mathrm{mg}$. In addition, chlorambucil was stopped and monthly rituximab (first dose $375 \mathrm{mg} / \mathrm{m}^{2}$, subsequent doses $500 \mathrm{mg} / \mathrm{m}^{2}$ ) was administered. After 6 months, her lymphocyte count was normal and serum creatinine level was around $142 \mu \mathrm{mol} / \mathrm{L}$. Proteinuria also reduced to $1.12 \mathrm{~g} / \mathrm{day}$ and her last anti-MPO level was $11 \mathrm{U} / \mathrm{mL}$.

\section{Discussion}

We present a rare case of a 71-year-old woman with ANCA-associated crescentic glomerulonephritis that occurred simultaneously with renal infiltration of CLL. Such leukaemia is one of the chronic lymphoproliferative disorders characterised by a progressive accumulation of functionally incompetent lymphocytes that are monoclonal in origin. In fact, CLL can be considered to be identical to the mature (peripheral) B cell neoplasm small lymphocytic lymphoma (SLL) but at different stages along a continuum. Patients in an early stage of CLL are usually asymptomatic. The most common presentation is the incidental finding of leukocytosis, especially lymphocytosis. Other presenting signs and symptoms include malaise, weakness, anaemic symptoms, night sweating, recurrent infection, and lymphadenopathy. The diagnosis of CLL requires demonstration of lymphocytes with monoclonal B cells in either serum or bone marrow. Monoclonal B cells can be demonstrated by the expression of CD5 antigen.

The disease CLL/SLL is commonly associated with various glomerular disease entities such as minimal-change glomerulopathy, membranoproliferative glomerulonephritis, membranous glomerulopathy, focal segmental glomerulosclerosis, light-chain deposition disease, amyloidosis, and immunotactoid glomerulopathy. ${ }^{1}$ In addition, CLL can infiltrate various internal organs such as the kidneys. Previous studies have shown on autopsy that the kidneys were involved in $60 \%$ to $90 \%$ of CLL cases. ${ }^{2,3}$ Renal infiltration of CLL can be easily missed however, because it is usually 
asymptomatic and is not a common cause of acute kidney injury or end-stage renal disease. ${ }^{4,5}$ As a result, the interstitial inflammatory cell infiltrate in the renal biopsy specimen should be examined with immunofluorescence and electron microscopy.

Moreover, CLL can also be associated with autoimmune diseases, notably haematological diseases such as haemolytic anaemia, thrombocytopenia, and pure red cell aplasia. ${ }^{6}$ Approximately $2 \%$ of patients with CLL have associated pANCA positivity. ${ }^{7}$ Titre of ANCA has been shown to be involved in the pathogenesis of pauci-immune crescentic glomerulonephritis. ${ }^{8}$ Hence, it is not surprising that CLL can be associated with rapidly progressive glomerulonephritis (RPGN). The association between CLL/SLL and RPGN, however, has been shown in only a few case reports, and while renal histology was lacking in some of these patients, most of them were found to have positivity for pANCA and anti-MPO when serologic tests were available. ${ }^{1,9-14}$

There have been no large-scale randomised controlled trials for the treatment of CLL-related pauci-immune glomerulonephritis because of the limited number of patients. Most reported cases have been treated in the same way as other pauci-immune glomerulonephritis. ${ }^{9} \quad$ Medication used in the treatment of RPGN such as steroid, cyclophosphamide, chlorambucil, and rituximab can also be used to treat CLL. In comparison, the combination chemotherapy for high-risk CLLwhich includes fludarabine, cyclophosphamide, and rituximab-shows a higher complete response rate. ${ }^{15}$ It has been postulated that successful treatment of CLL will eventually result in resolution of RPGN.

In conclusion, we report a rare case of anti-MPO antibody-related crescentic glomerulonephritis in a patient with a known history of CLL. Awareness of this rare complication in patients with CLL with early screening, close follow-up of renal function, and timely appropriate treatment are important. Further trials may be required to determine definitive treatment when these diseases co-exist.

\section{References}

1. Moulin B, Ronco PM, Mougenot B, Francois A, Fillastre JP, Mignon F. Glomerulonephritis in chronic lymphocytic leukemia and related B-cell lymphomas. Kidney Int 1992;42:127-35.

2. Barcos M, Lane W, Gomez G, et al. An autopsy study of
1206 acute and chronic leukemias (1958 to 1982). Cancer 1987;60:827-37.

3. Schwartz J, Shamsuddin A. The effects of leukemic infiltrates in various organs in chronic lymphocytic leukemia. Hum Pathol 1981;12:432-40.

4. Boudville N, Latham B, Cordingly F, Warr K. Renal failure in a patient with leukaemic infiltration of the kidney and polyomavirus infection. Nephrol Dial Transplant 2001;16:1059-61.

5. Hewamana S, Pepper C, Jenkins C, Rowntree C. Acute renal failure as the presenting feature of leukaemic infiltration in chronic lymphocytic leukaemia. Clin Exp Nephrol 2009;13:179-81.

6. Diehl LF, Ketchum LH. Autoimmune disease and chronic lymphocytic leukemia: autoimmune hemolytic anemia, pure red cell aplasia, and autoimmune thrombocytopenia. Semin Oncol 1998;25:80-97.

7. Cil T, Altintas A, Isikdogan A, Batun S. Prevalence of antineutrophil cytoplasmic antibody positivity in patients with Hodgkin's and non-Hodgkin lymphoma: a single center experience. Int J Hematol 2009;9:52-7.

8. Xiao H, Heeringa P, Hu P, et al. Antineutrophil cytoplasmic autoantibodies specific for myeloperoxidase cause glomerulonephritis and vasculitis in mice. J Clin Invest 2002;110:955-63.

9. Henriksen KJ, Hong RB, Sobrero MI, Chang A. Rare association of chronic lymphocytic leukemia/small lymphocytic lymphoma, ANCAs, and pauci-immune crescentic glomerulonephritis. Am J Kidney Dis 2011;57:170-4.

10. Biava CG, Gonwa TA, Naughton JL, Hopper J Jr. Crescentic glomerulonephritis associated with nonrenal malignancies. Am J Nephrol 1984;4:208-14.

11. Rivera M, González C, Gonzalo A, Quereda C, Fogué L, Ortuño J. Vasculitis associated with non-Hodgkin's lymphoma. Nephron 1993;65:167-8.

12. Dussol B, Brunet P, Vacher-Coponat H, Bouabdallah R, Chetaille P, Berland Y. Crescentic glomerulonephritis with antineutrophil cytoplasmic antibodies associated with chronic lymphocytic leukaemia. Nephrol Dial Transplant 1997;12:785-6.

13. Tisler A, Pierratos A, Lipton JH. Crescentic glomerulonephritis associated with p-ANCA positivity in fludarabine-treated chronic lymphocytic leukaemia. Nephrol Dial Transplant 1996;11:2306-8.

14. Hamidou MA, El Kouri D, Audrain M, Grolleau JY. Systemic antineutrophil cytoplasmic antibody vasculitis associated with lymphoid neoplasia. Ann Rheum Dis 2001;60:293-5.

15. Robak T, Dmoszynska A, Solal-Céligny P, et al. Rituximab plus fludarabine and cyclophosphamide prolongs progression-free survival compared with fludarabine and cyclophosphamide alone in previously treated chronic lymphocytic leukemia. J Clin Oncol 2010;28:1756-65. 